\title{
Identidade profissional docente: interfaces de um processo em (re)construção
}

\author{
Maria da Conceiçáo Valença da Silva*
}

Maria da Conceição Carrilho de Aguiar**

Ivanilde Alves Monteiro***

\section{Resumo}

O processo de (re)construção da identidade profissional docente emerge como temática significativa, cujo foco de estudo envolve a constituição do ser professor. Nesse sentido, esta investigação tem como objetivo refletir o processo de construção da identidade profissional docente, a fim de favorecer uma compreensão dos aspectos nele envolvidos. Para tanto, buscou-se contribuiçôes de estudos que tratam acerca dessa temática, notadamente voltados para essa constituição no âmbito da educação superior. $\mathrm{O}$ presente trabalho, ancorado na abordagem de pesquisa qualitativa, foi dividido nas seguintes temáticas: Conceitos de Identidade e Identidade Profissional, no sentido de basilar as reflexóes tecidas ao longo do estudo; e Identidade Profissional Docente: exigências e desafios circunstanciais, com ênfase para esse processo na Educação Superior. Ressalta-se, nas consideraçóes (in)conclusivas, que a identidade não é o alicerce da unidade de um grupo, ela é resultante dos processos de identificação e distinção pelos quais um grupo busca formar a sua coesão e marcar a sua posição em relação aos outros grupos. O processo de (re)construção da identidade profissional docente é complexo e vai se constituindo em diferentes espaços e tempos através de variadas trajetórias, sendo individual e coletivo, numa permanente reinvenção de relaçóes pessoais e profissionais compartilhadas culturalmente.

Palavras-chave: Identidade Profissional. Formação Docente. Ensino Superior.

\footnotetext{
* Doutora em Educaçáo pela Universidade Federal do Pernambuco (UFPE). Procuradora Institucional da Faculdade de Filosofia, Ciências e Letras de Caruaru (FAFICA). Professora da Faculdade da Associação Caruarense de Ensino Superior (ASCES).

** Doutora em Ciências da Educação pela Universidade do Porto, Portugal. Professora do Centro de Educação e da Pós-Graduação em Educação da Universidade Federal de Pernambuco (UFPE).

*** Doutora em Educação pela Universidade do Minho, Portugal. Professora do Centro de Educação e da Pós-Graduação em Educação da Universidade Federal de Pernambuco (UFPE).
} 


\section{Introdução}

O atual cenário societário, complexo e multideterminado nos motiva a buscar diversos conhecimentos e a (re)elaborar novos e velhos saberes, a partir de contribuiçóes teóricas, na perspectiva de que, ao compreendermos melhor a realidade, provavelmente poderemos explicá-la mais e intervir.

O processo de buscar entender o sentido da vida, o ser humano e as realidades, cujos fenômenos emergem aparentemente sem explicação, desde sempre inquietou o ser humano e o instiga a querer compreender suas origens e identidades ${ }^{1}$. Nessa caminhada de busca por respostas, vários fatores devem ser considerados, uma vez que tanto os seres humanos quanto os fenômenos vão se constituindo em dados tempos/espaços e são influenciados por fatores históricos, políticos, sociais, religiosos, filosóficos e culturais, num contexto complexo, inter-relacional. Nessa perspectiva, elegemos, como objetivo deste estudo, refletir o processo de (re) construçáo da identidade profissional docente na Educação Superior.

$\mathrm{Na}$ trilha de um percurso reflexivo acerca do objeto de estudo, este texto foi construído contemplando as seguintes temáticas: Conceitos de Identidade e Identidade Profissional, no sentido de basilar as reflexóes tecidas ao longo desta investigação; e Identidade Profissional Docente: exigências e desafios circunstanciais, com ênfase para a construção dessa identidade no âmbito da Educação Superior, a partir de um recorte dos dados empíricos desta pesquisa coletados com docentes de duas instituições de Educação Superior, a fim de favorecer a compreensão de processos de construção da identidade profissional do professor. Finalmente, anunciamos as consideraçôes circunstanciais dos estudos desenvolvidos, com destaque para os fatores relevantes implícitos no processo de construção da identidade profissional docente.

Neste texto, é feita uma breve referência ao paradigma da complexidade, conforme defende Morin $(2000,2001)$ e Capra (1996), para evidenciar que a emergência desse paradigma se dá num contexto de inquietações, conflitos, dúvidas e desafios que exigem a superação da visão linear, fragmentada e reducionista da realidade. Nesse sentido, a complexidade é concebida numa visão de conexão, de teia, de rede que requer uma reforma profunda de pensamento (MORIN, 2000, 2001). Devido à crise paradigmática que ora presenciamos, verifica-se a necessidade de visão da totalidade dos fenômenos, visto que os sistemas não podem ser entendidos pelas partes. Capra (1996) nos 
ajuda nessa reflexão quando esclarece que a natureza do todo é sempre diferente da mera soma de suas partes.

Buscando estabelecer uma relação entre o paradigma da complexidade e a construçấo de processos identitários, observamos que a identidade do ser humano contemporâneo (social, histórico, político, psicológico, emocional, criativo, criador etc.) vai se modificando e sendo construída e reconstruída devido às incertezas de um contexto complexo que impóe mudanças nas relações sociais e, consequentemente, na construção de suas identidades - no caso específico deste estudo, das identidades pessoal e profissional do docente.

Nesse cenário, o processo de construção da identidade profissional do professor emerge como temática significativa, cujo foco de estudo envolve a constituiçấo do ser professor.

\section{Conceitos de identidade e identidade profissional}

\section{Do conceito de identidade}

Partindo do entendimento de que a identidade do ser humano vai se construindo a partir das mudanças que ocorrem nos mais diversos contextos sociais, exigindo uma (re)elaboração de visões e uma (re)construção de saberes, é válido, inicialmente, refletir sobre conceitos de identidade e formas de identificação tratados por alguns estudiosos dessa temática, no sentido de melhor compreendermos os processos de construçáo da identidade profissional docente, uma vez que, neste texto, esse é o foco da reflexão/discussão.

Nos estudos sobre identidade, um autor que tem contribuído significativamente é Zygmunt Bauman (2005). Situando a construção da identidade no mundo globalizado, esse autor evidencia a emergência de novos parâmetros da sociedade contemporânea e ressalta as dinâmicas contextuais do chamado "mundo líquido", cujos reflexos se expressam no processo identitário. Diz Bauman (2005) que o pertencimento e a identidade não têm a solidez de uma rocha, não são garantidos para toda a vida, mas são, sim, bastante negociáveis e revogáveis.

Com efeito, o autor chama a atençấo para o fato de que, diante das mudanças desse "mundo líquido", a construção identitária não está dada para sempre, ao contrário, a identidade vai se constituindo num processo permanente de inconclusão e reconstrução. Para uma melhor compreensão desse processo 
de construção da identidade, faremos uma reflexão sobre alguns fundamentos que consideramos basilares para esse tema.

Dubar (2006), em seu texto $A$ crise das identidades: a interpretação de uma mutação, destaca duas grandes correntes que embasam conceitos de identidade: a) Corrente Essencialista, que acredita nas essências, nas realidades essenciais, nas substâncias imutáveis e originais; e b) Corrente Existencialista, que postula que não há essências eternas, uma vez que tudo é submetido à mudança.

Essas visôes que respaldam diferentes conceitos de identidade divergem em seus fundamentos, dado que, se numa abordagem a base é a essência herdada, na outra, é a existência contingente que dá sustentação à construção da identidade, devido ao seu caráter variável; ou seja, a identidade vai se configurando dependendo dos modos de identificação. Nessa perspectiva, é a relação entre as formas de identificação atribuídas pelos outros (identificações para outro) e as identificaçōes reivindicadas por si próprio (identidades para si) que constituem, segundo Dubar (2006), a base das formas identitárias, numa via de mão dupla, em que as identificações para outro se inter-relacionam com a identidade para si.

Ao dispor sobre esse processo, o autor evidencia formas identitárias como modos de identificação dos indivíduos, a partir de dois eixos: o biográfico e o relacional. Quanto ao primeiro, temos o biográfico para outrem, que provém da inscrição dos indivíduos numa linhagem de geraçóes, e o biográfico para si, ou seja, é "esta história que cada um conta a si próprio sobre aquilo que é"; esse "Si" narrativo expressa a necessidade que cada um tem de se ver reconhecido não só pelos "Outros significativos", mas também pelos "Outros generalizados". Em relação ao segundo eixo, temos o relacional para outrem, que constrói-se sob pressão de integração às instituiçóes, como a família, a escola, os grupos profissionais, o Estado; e implica num "Eu socializado" através do desempenho de papéis, e o relacional para si, que provém duma consciência reflexiva (DUBAR, 2006, p. 51).

Numa visão próxima a de Dubar (2006), Erikson (1972) entende que a identidade se constrói em consonância com o juízo que o indivíduo faz de si próprio, tendo como referência os seus julgamentos sobre os outros, os julgamentos dos outros sobre ele próprio, assim como o contexto em que este está inserido. Entretanto, Aguiar (2004) afirma que, apesar da diversidade e da mutabilidade das situaçóes, o indivíduo guarda um sentimento de unidade e continuidade através do qual é reconhecido por si e pelos outros como sendo ele mesmo. 
Ainda no âmbito das abordagens acerca da identidade, Erikson (1972) considera que a introjeção, a identificação e a formação da identidade são fases através das quais o ego se desenvolve, numa relação madura com os modelos existentes. Para ele, a introjeçáo é a incorporação primitiva da imagem de outrem; o destino das identificações dependerá da interação do indivíduo com representantes de uma significativa hierarquia de papéis; e a formação da identidade começa quando termina a utilidade da identificação. Assim, continua o autor, os métodos de uma comunidade para identificar o indivíduo se encontram, com maior ou menor êxito, com os métodos do indivíduo para identificar-se a si próprio com os outros (ERIKSON, 1972, p.160).

Desse modo, num processo de constituição identitária, as formas de identidade são inseparáveis das relações sociais, as quais são também formas de alteridade; ou seja, não existe identidade sem relaçáo entre o si próprio e o outro.

Em se tratando da constituição dessa identidade, Dubar (2005) apresenta a hipótese de que existem vários tipos de identidade pessoal, várias maneiras de construir identificações de si próprio e dos outros e vários modos de construção da subjetividade, ao mesmo tempo social e psíquica. Contudo, esse é um processo em que ocorrem crises. Tais crises acontecem e se multiplicam em todas as idades, e são geradoras de "pequenas crises". Daí a necessidade de um "trabalho sobre si", uma modificação de certos hábitos. Por vezes, é preciso aprender outra vez, recomeçar, diz o autor.

Várias são as razóes que provocam crises de identidade. Essas crises cortam o curso da vida, engendrando perdas materiais, perturbaçóes relacionais, mudanças da subjetividade, dentre outros aspectos, como afirma Dubar (2006). Segundo esse autor, tais crises são de caráter identitário porque perturbam a imagem de si, a estima de si, a própria definição que a pessoa dava "de si a si próprio". Nesse sentido, ainda conforme Dubar (2006), qualquer mudança de configuração identitária passa por esse tipo de crise, o que implica na reconstrução de uma nova identidade pessoal.

Assim entendida, a identidade nunca é instalada, nunca é acabada, visto que o entorno do Ego é móvel e que os indivíduos passam necessariamente por crises de identidade ligadas a fissuras internas do Ego, como afirma Erikson, referido por Dubar (2005).

Considerando a articulação entre identidade para si/ identidade para outro, diz Dubar (2005) que a identidade pode ser incluída numa perspectiva 
sociológica pela restituição dessa relação ao interior do processo comum que a torna possível e que constitui o processo de socialização. Com efeito, a identidade nada mais é do que o resultado - a um só tempo "estável e provisório, individual e coletivo, subjetivo e objetivo, biográfico e estrutural - dos diversos processos de socializaçáo que, conjuntamente, constroem os indivíduos e definem as instituiçôes" (DUBAR, 2005, p. 136).

A partir das reflexôes até aqui tecidas em torno das variáveis inerentes à configuração do processo identitário, adota-se que "a identidade não é aquilo que permanece necessariamente 'idêntico', mas o resultado de uma identificação contingente" (DUBAR, 2005, p.8), em cujo processo ocorrem crises.

\section{Da identidade profissional}

Seguindo o objetivo deste estudo de refletir o processo de construção da identidade profissional docente, estamos utilizando como base o conceito de identidade anteriormente anunciado: enquanto um processo que não é linear, e que está em constante (re)construção, consideradas as circunstâncias em suas várias dimensóes e contextos. Para tanto, avancemos com as reflexóes, a fim de tecer algumas consideraçóes acerca, especificamente, da identidade profissional.

Ao referir-se às identidades profissionais, Dubar (2006) as define como maneiras socialmente reconhecidas de os indivíduos se identificarem uns aos outros no campo do trabalho e do emprego. Ou seja, como complementa Lopes (2001, p. 188), é uma "identidade social particular que decorre do lugar das profissóes e do trabalho no conjunto social e, mais especificamente, do lugar de uma certa profissão e de um certo trabalho na estrutura da identidade pessoal e no estilo de vida do ator".

Esse percurso de construção de identidade profissional vai se efetivando, segundo Dubar (2005), através de uma dupla transação (biográfica e relacional): de identidade para si (transação interna ao indivíduo) e de identidade para o outro (transação externa entre o indivíduo e as instituições), ambas articuladas e processadas por meio de mecanismos de pertencimento (que tipo de homem ou mulher se quer ser/ se diz ser) e de atribuição (que tipo de homem ou mulher você é/ dizem que você é).

A partir de outra perspectiva, diz-nos Sainsaulieu (1985) que o processo identitário profissional se constrói de acordo com a forma como os grupos no trabalho se identificam com os pares, com os chefes e com os outros grupos, 
a identidade no trabalho, complementa o autor, é fundada nas representações coletivas distintas, construindo atores do sistema social empresarial. Observa-se que esse conceito situa a identidade na experiência relacional e social de poder. Há, no processo de construção da identidade, um desejo de ser reconhecido pelo outro, porém, conforme destaca o autor, o desejo de reconhecimento passa pela possibilidade de o indivíduo sair vencedor nas relaçóes de poder e de fazer reconhecer a plena autonomia de seus significados.

Ainda quanto a essa definição, Dubar (2005) comenta que, na perspectiva de Sainsaulieu, a identidade é menos um processo biográfico de construção de si que um processo relacional de investimento de si. Tal observação é evidenciada também por Lopes (2001), quando se refere às visōes de Dubar e de Sainsaulieu, no qual destaca que, na primeira visão, a identidade profissional é concebida como resultante momentânea da dupla transação identitária, a ênfase é na transação biográfica e nas configuraçôes identitárias pessoais; enquanto que, na segunda, a identidade no trabalho é concebida como interestruturação dos sujeitos e das dinâmicas relacionais da sua atividade de trabalho, são enfatizadas a transação relacional e os modelos identitários coletivos.

Contudo, infere Lopes (2001, p.207), referindo-se às visóes de Dubar e de Sainsaulieu, que esses processos: "são igualmente fornecedores de elementos para aspectos essenciais a identificar para um modelo de formação e investigação da construção de identidades especializadas, em tempos de modernidade tardia e no registro da esperança”.

Como pudemos observar nesse percurso de reflexão de conceitos de identidade e de identidade profissional, os estudos acerca dessa temática vão contribuindo para um melhor entendimento dos fatores relacionados à construçâo da identidade profissional docente.

\section{Identidade profissional docente: exigências e desafios circunstanciais}

A partir das reflexôes teóricas até então tecidas, cujas contribuições vão elucidando aspectos relacionados à constituição da identidade pessoal e profissional, passemos a refletir outros fatores que, articulados aos já referidos, poderão favorecer uma melhor compreensão da identidade profissional docente. 
Considerando que a identidade profissional docente, igualmente a outras identidades profissionais, tem suas especificidades, trataremos, brevemente, da trajetória da profissão professor, para situarmos o seu processo de construção identitária.

\section{Profissão Docente: recortes contextuais de uma trajetória}

No intuito de pensarmos a construção da identidade profissional docente, faremos, de forma muito sucinta, uma incursão na trajetória da profissão docente no Brasil, a fim de evidenciarmos alguns contextos e circunstâncias relacionados ao processo de construção identitária dessa profissão.

Apesar de este trabalho não ter o objetivo de aprofundar a dimensão histórica da profissão docente, é importante, nesse momento do estudo, destacar alguns recortes contextuais da história dessa profissão no âmbito da educação brasileira, uma vez que, ao longo desse percurso, várias identidades profissionais docentes foram sendo construídas, em diferentes tempos/espaços, considerados os aspectos sociais, políticos e culturais dos mais diversos contextos.

Nessa retomada histórica, lembramos que, a partir da chegada dos jesuítas ao Brasil, o trabalho docente passou a ser considerado um ofício destinado à transmissão de princípios e valores morais religiosos, em que a atuação do professor era identificada pela vocação. $\mathrm{O}$ trabalho docente foi marcado, nesse período, como missão divina. Mais adiante, já no século XVIII, mesmo havendo a estatização da educação, o modelo de professor continuou semelhante ao de padre (ROMANELLI, 1997).

A partir da Lei Geral do Ensino, instituída no século XIX, deu-se início à normatização da profissão, inclusive por meio de seleção de professores e exigência de um treinamento para a atuação docente. Esses fatores caracterizam um processo de profissionalização docente, uma vez que definem um perfil de competências para o recrutamento dos professores (ROMANELLI, 1997). A esse respeito, Monteiro (2004) destaca que os processos de urbanização e industrialização impuseram a constituição de um sistema público de educação e, assim, a carreira docente passou a ser organizada. Entretanto, ocorreu o aumento do controle estatal sobre a atividade docente, o que exerceu um maior controle sobre a organização do sistema, do currículo e do trabalho do professor.

Após o período em que o professor foi visto como protagonista (quando o papel da educação foi reconhecido como ferramenta essencial para o progresso 
do país, no século XIX), houve, devido ao advento do capitalismo (quando as escolas passaram a atender às exigências mercadológicas, cabendo-lhes preparar os cidadãos para o mercado de trabalho), a desvalorização do trabalho docente. A atuaçáo do professor, portanto, passou a se concretizar pautada numa perspectiva normativa e prescritiva, cuja visão vai influenciar a legislação educacional do país.

Só no final da segunda metade do século XX começam a emergir interesses voltados para a formação e atuação dos professores, como alternativa para a melhoria da educação de alguns países, inclusive do Brasil.

Percebe-se, dessa maneira, a partir dessa breve incursão na trajetória da profissão docente, que as identidades atribuídas a essa profissão têm se modificado mediante as circunstâncias e interesses sociopolíticos, ora em prol da profissão, ora em detrimento de uma identidade que favoreça o status profissional docente.

Nesse cenário de discussão, é mister ressaltar o alerta de Sheibe (2010) acerca da necessidade de implementação de políticas consistentes, coerentes e contínuas de formação inicial e continuada dos professores (sejam eles da educação básica ou da educação superior), no sentido de melhorar as suas condições de trabalho, de carreira e de remuneração, uma vez que o atual debate educacional está inserido no contexto de definição das proposiçóes para o Plano Nacional de Educação $(2011$ - 2020). Portanto, em pleno século XXI vários são os desafios que se impóem para a educação, principalmente aqueles referentes à atuação do professor, temática tratada adiante.

\section{(Re) construção da identidade profissional docente na educação superior: provocações reflexivas}

$\mathrm{Na}$ contemporaneidade, emergem desafios de ordem social, tecnológica, científica, entre outros, cujas exigências requerem uma reflexão permanente sobre o processo de (re)construção da identidade pessoal/ profissional dos educadores.

No cenário mundial, marcadamente a partir do final do século XX e início do século XXI, ressurgiu certa atenção para a Educação Superior como possibilidade de busca de melhoria da qualidade da educação, em diversos países. A exemplo de mudanças no cenário internacional, ganharam relevo algumas derivadas da Declaraçáo de Bolonha, movimento de reforma e integração da Educação Superior na Europa, com o objetivo de incentivar a 
mobilidade entre países. Para Serralheiro (2005, p.20) o desenvolvimento do conhecimento e do ensino nada ganham se o Processo de Bolonha for colocado a serviço das estratégias que visam à mercantilização do ensino e da formação e o aniquilamento do ensino público.

São evidentes também mudanças em sistemas de Educação Superior na América Latina, derivadas de influências de organismos de caráter neoliberal, como o Banco Mundial, mediante disponibilização de financiamentos, documentos, diagnósticos, estratégias enquanto referências para reformas educacionais (GENTILI, 2001; DOURADO, 2002; ARRUDA, 2011).

No caso do Brasil, as mudanças na Educação Superior foram e são concretizadas ao longo da história da educação no país, circunstanciadas por iniciativas sociais, políticas, econômicas, ora identificadas como avanços, ora caracterizadas pelas restrições ao processo de organização e gestão das instituiçóes educacionais, bem como às necessidades básicas da comunidade acadêmica. Se a atenção que ressurgiu para a Educação Superior, subsidia (ou deveria subsidiar) a implementação de políticas públicas, alguns aspectos precisam ser considerados nesse ínterim, a saber: a valorização do magistério, a formação do professor, as condiçóes do trabalho docente, o processo de formação dos estudantes, a autonomia universitária, a construção dos projetos pedagógicos institucionais, $\mathrm{o}$ acesso e a permanência na Educação Superior, dentre outros fatores importantes, no sentido de buscar melhorias para a educação em nosso país.

Decerto nesse percurso exigências vão se impondo à construção da formação e da identidade profissional docente, como o fortalecimento de uma dimensão ética, no sentido de viabilizar a educação enquanto meio para a construção da humanização do ser humano; de uma dimensão técnica, que o torne capaz de integrar conhecimentos, competências e habilidades a fim de qualificar a atuação docente; e de uma dimensão política, para possibilitar entender e explicar a realidade, tomar decisōes, assumir posiçóes críticas diante de situações conjunturais e, finalmente, intervir no processo de transformação da sociedade e de nós mesmos, enquanto sujeitos inconclusos, culturais.

Ao longo da história da educação brasileira, docentes têm pleiteado reconhecimento e valorização social da profissão. No processo de construção da identidade profissional do professor, várias são as exigências e demandas da sociedade, considerados os contextos e interesses sociais, políticos, culturais. Daí que a identidade profissional docente vai adquirindo novas características, em diferentes espaços e tempos; ou seja, parafraseando Pimenta (1999), o 
indivíduo vai construindo sua identidade profissional considerando a constante revisão dos significados sociais da profissão, dos confrontos teórico-práticos, do significado que cada professor atribui à atividade docente, das suas experiências, representaçōes, saberes etc.

Ainda nesse processo identitário, outro fator a ser considerado é a identidade das instituiçōes de Educação Superior, como afirmam Franco e Gentil (2007), no sentido de que as Instituiçóes de Educação Superior guardam diferentes aspectos, características, objetivos relacionados ao trabalho que o professor realiza, influenciando na construção da identidade docente:

os objetivos que se alteram, são substituídos ou acrescidos de outros, transformando as identidades. Assim, os objetivos institucionais estão no cerne dos elementos que se unem e contribuem na constituição de identidades dos que trabalham numa dada instituição. na medida em que trabalho é aspecto produtor de significados, é constitutivo de identidades. [...] nas IES [Instituiçóes de Educação Superior] os departamentos, os grupos de trabalho, os grupos de pesquisa são espaços de construção de identidade e os formatos por eles assumidos são ancorados em finalidades e em relaçóes institucionais e povoam as construçóes identitárias do professor de ensino superior. (FRANCO; GENTIL, 2007, p. 12).

Cabe lembrar que é, sobretudo, através da atuação do professor no âmbito da instituição educacional que ele vai estabelecer relaçôes e constituir sentimentos identitários profissionais.

Ao tratar sobre ciclos de vida da profissão docente, Cristina D'Ávilla (2009) ressalta que a identidade profissional docente não se inicia na socialização formal, mas atravessa diferentes fases, a saber: socialização préprofissional (subjetiva, complexa, informal, diz respeito à trajetória de cada um) e socialização profissional (diz respeito à formação inicial que inaugura a profissionalização da docência; é uma fase mais formal). Nessa mesma linha de pensamento e inferência, Souza (2012), num estudo com professores de licenciatura, concluiu que esta identidade é um processo contínuo que além de ser iniciado com a experiência pré-profissional, passa pela escolha da profissão e se fortalece na formação inicial e nos primeiros anos de trabalho. 
Com efeito, a identidade profissional docente é permeada por variadas interações: seja pelas histórias de vida dos professores, pela formação, pelo conhecimento especializado do docente, pelas relaçôes com o grupo profissional, pelo conhecimento das especificidades da profissão e de sua prática, ou ainda pela singularidade dos sujeitos, dentre outros fatores relacionados à construção de uma identidade. De acordo com Aguiar (2004), a construção da identidade profissional dos docentes (enquanto grupo profissional) está ligada às relaçôes que estes mantêm com as instituiçóes empregadoras e às consequentes transformações dos sistemas educativos.

Nessa mesma perspectiva, Monteiro (2004) entende a identidade profissional docente enquanto construção social, em que os professores têm um papel central. Entretanto, ressalta a autora que o contexto local em que o professor exerce a docência, com suas implicaçôes políticas, sociais e culturais, e o local da formação inicial também estáo relacionados à construção e à transformação identitária, propiciando o desenvolvimento de novas culturas profissionais.

No caso específico desta pesquisa, na primeira fase de coleta dos dados empíricos, aplicamos um questionário para um total de 130 professores (licenciados ${ }^{2}$ e bacharéis ${ }^{3}$ ), de vários cursos de graduação, em duas instituições de Educação Superior, locus da pesquisa, sendo uma pública e outra privada. A quantidade de docentes foi proporcional ao número de professores licenciados e bacharéis, de acordo com os cursos ofertados em cada instituição. Orientados pelo objetivo deste estudo, apresentamos no quadro 1 um recorte dos dados coletados, para subsidiar reflexóes inerentes à formação inicial desses professores, enquanto um aspecto relacionado à construçâo da identidade profissional docente

Quadro 1 - Demonstrativo da formaçáo inicial de professores licenciados e bacharéis de duas instituiçóes pública e privada

\begin{tabular}{|c|c|c|c|}
\hline $\begin{array}{c}\text { Instituição } \\
\text { de Educação } \\
\text { Superior }\end{array}$ & $\begin{array}{c}\text { No de } \\
\text { professores que } \\
\text { responderam o } \\
\text { questionário }\end{array}$ & $\begin{array}{c}\text { No de professores } \\
\text { licenciados }\end{array}$ & $\begin{array}{c}\text { No de professores } \\
\text { bacharéis }\end{array}$ \\
\hline Pública & 65 & 22 & 43 \\
\hline Privada & 65 & 34 & 31 \\
\hline Fonte: Autoras
\end{tabular}


Somadas as quantidades de professores das duas instituiçóes temos o seguinte: 56 professores licenciados; e 74 professores bacharéis. Este resultado reflete a realidade de boa parte, ou talvez, da maioria das instituiçóes de Educação Superior que tem seu corpo docente constituído por (bacharéis) profissionais liberais, cientistas, funcionários públicos que não dispuseram de saberes específicos da docência em sua formação inicial.

A formação de professores universitários, no sentido de qualificação científica e pedagógica, parece se apresentar como um dos aspectos básicos da qualidade da universidade (ZABALZA, 2004). Essa assertiva sinaliza que apesar das diferentes formaçôes da maioria dos professores de graduação, todos têm em comum a função docente. Embora os conteúdos disciplinares sejam distintos, as questóes próprias da docência no que concerne ao ensino, ao planejamento, à avaliação, à metodologia, dentre outros aspectos que conformam a organização do trabalho docente, são comuns a todos.

Para Cunha (2010, p. 292), não há um reconhecimento da importância da formação do professor para o exercício da docência na Educação Superior, "os conhecimentos que fazem parte de sua estrutura são pouco valorizados, em decorrência da condição histórica da docência, baseada em saberes do senso comum". Diante desse contexto de embates e requerimentos para a docência na Educação Superior, urge uma atenção maior das instituições educacionais, bem como dos seus protagonistas/professores às questóes referentes à atuação docente, à formação e aos saberes dos professores como fatores relevantes caracterizadores da profissão de professor, consequentemente da sua identidade profissional.

$\mathrm{Na}$ relação da construçâo identitária com a formaçâo do professor e com a profissionalização da docência, alguns desafios emergem, como o reconhecimento social ou não da profissão, as repercussóes da ausência de políticas públicas para formação do professor da Educação Superior, a qual fica a mercê, na maioria das vezes, dos interesses das instituiçóes educacionais e/ou dos próprios professores.

Outros dados empíricos desta pesquisa, coletados com a aplicação do questionário, são referentes ao processo de aprendizagem da docência, cuja pergunta feita aos professores foi a seguinte: como você aprendeu elou aprende a ser professor? Das respostas a esta questão, destacamos algumas tanto de professores $^{4} \mathrm{da}$ instituição pública (IPub.) quanto da instituição privada (IPri): 
Não houve um aprendizado formal, apenas observando meus próprios professores e a própria prática. (P12 IPub.).

Através da observação dos meus professores, em maior parte, e através da experiência adquirida no exercício da profissáo. (P18 IPub.).

Através da disciplina de Didática do Ensino Superior, leituras, discussóes com outros professores, e principalmente na interação com os alunos. (P53 IPub.).

Acredito que a formação como professor começou quando era aluno nas escolas que passei na infância e adolescente. $O$ curso de licenciatura também ajudou, mas foi na fase que fui professor da Educação Básica que aprendi realmente a ser professor. (P27 IPub.).

A partir das falas dos docentes, observamos que há professores que dizem ter aprendido a ser professor tanto com o curso de licenciatura como com curso específico para aquisição de saberes próprios da docência. Outros, entretanto, referem-se aos saberes da experiência, aqueles adquiridos no dia a dia da atuaçẫo docente, além daqueles dos exemplos dos seus professores.

Corroboram com essa reflexão Tardif e Lessard (2007, p. 51), ao lembrarem que "quando se interrogam professores a respeito de suas próprias competências profissionais, é na maioria das vezes a essa visão de experiência que eles se referem implicitamente, para justificar seu 'saber ensinar'". As experiências vivenciadas embora contribuam para o processo educacional, não dáo conta da complexidade e necessidades do professor como mediador do processo de ensino e aprendizagem. Os saberes necessários à docência, para além dos da experiência, abrangem saberes curriculares, disciplinares, pedagógicos, ancorados pela pesquisa, pela criticidade, pelo diálogo etc. (FREIRE, 1997; PIMENTA, 1999; TARDIF, 2002).

Quanto aos depoimentos de professores da instituição privada, eis algumas respostas à questáo como você aprendeu elou aprende a ser professor?:

Eu sempre selecionei alguns docentes que marcaram minha vida e desejo imitá-los, mas com melhorias, adaptaçôes e bastante de mim mesmo. (P6 IPriv.). 
Com as práticas cotidianas, com leituras e troca de experiências com colegas. (P9 IPriv.).

Através da formaçấo inicial e continuada paralelamente com a docência na Educação Básica e no Ensino Superior. (P5 IPriv.).

No meu curso de licenciatura eu paguei disciplinas específicas à prática docente. (P53 IPriv.).

Com efeito, a construção da identidade profissional de professores que exercem a docência na Educação Superior, vai se dando numa teia de diferentes e variadas interfaces, espaços e tempos nos quais são consideradas tanto as concepçôes de mundo, de sociedade, de ser humano e de educação do docente quanto sua formaçáo, sua trajetória profissional (seja na docência e/ou em outra profissão), as especificidades da sua área de atuação disciplinar, suas relações com as instituições onde trabalha ou trabalhou, suas práticas, além das influências que emergem das relaçôes interpessoais com outros docentes e com os estudantes.

Algumas pesquisas (SUNDFELD, 2005; XIMENES, 2006, CAMARGO, 2012) mostram que os professores têm buscado investir na formação pessoal/ profissional, que há o reconhecimento da necessidade de formação contínua para possibilitar a aquisição de conhecimentos específicos da profissão docente. Entretanto, ainda são muito tímidas as iniciativas por parte das instituiçôes de Educação Superior. Esses resultados remetem-nos à compreensão de que tais condicionantes geram sentimentos positivos e/ou negativos, com influências na identidade profissional docente, bem como na construçáo da profissionalidade da docência.

Por outro lado, temos que considerar a visão que o professor tem quanto ao seu papel na Educação Superior, num determinado contexto, pois não basta o profissional ser um bom professor, a questão é: como um docente se torna um bom professor, desempenha bem o papel de pesquisador, realiza projetos de extensão e pode até ser um gestor competente.

Para estudar a identidade profissional do docente nesse nível de ensino, temos que estar cientes dos quatro eixos da função do professor nesse nível de ensino, uma vez que, para além do ensino, a pesquisa, a extensão e a gestáo, também estão inseridas na função do professor universitário, porém, geralmente, não são comentadas.

A necessidade de qualificação dos professores para o exercício da docência motivou a luta pela valorização do magistério da educação superior 
e suas consequentes conquistas expressas nos dispositivos do ordenamento jurídico-educacional brasileiro. Não é à toa que a Lei de Diretrizes e Bases da Educação Nacional (LDB), no 9.394/96, em seu título VI, art. 66, preconiza que "a preparação para o exercício do magistério superior far-se-á em nível de pós-graduação, prioritariamente em programas de mestrado e doutorado" (BRASIL, 1996). Embora se reconheça que tal dispositivo representa um avanço na questão da qualificação do professor para o exercício da docência nesse nível de educação, ele não resolve a questão da profissionalização do professor, já que o corpo docente dos cursos de graduação em nível de bacharelado é composto, em sua maioria, por profissionais liberais, cientistas, servidores públicos, dentre outros, que exercem a docência, mas que não dispõem de saberes pedagógicos, os quais nem sempre têm sido objeto de ensino dos cursos de pós-graduaçáo. É evidente que a formação pedagógica, seja inicial ou continuada, não garante por si só a qualidade do ensino; no entanto, considerando a complexidade da docência, admite-se que ela é um requisito imprescindível.

Bazzo (2008), ao discutir aspectos da carreira docente, analisa elementos relacionados à ambiguidade que acompanha a identidade do professor - mestre ou cientista. Ao referir-se aos dados obtidos em pesquisa realizada sobre a constituição da profissionalidade docente, essa autora destaca que os aspirantes a professor têm seus títulos valorizados muito mais em função de sua produção científica do que em qualquer outra evidência de que poderăo vir a ser "bons professores" (BAZZO, 2008). Este dado é ratificado na pesquisa de Dantas (2011), num estudo com professores de curso de Engenharia, onde há valorização da pesquisa e uma visão de que a docência se aprende na prática, embora reconheçam que náo é suficiente para o desenvolvimento profissional.

Considere-se, ainda, que no texto da LDB (BRASIL, 1996) fica clara a valorização da pesquisa em detrimento do ensino, uma vez que a qualificação do profissional através da pós-graduação stricto sensu é o requisito para o exercício da docência. Evidentemente, não se pretende negar a importância de se desenvolver a capacidade investigativa do professor na medida em que se reconhece ser esta uma condição para qualificar a docência. Entretanto, a nosso ver, os saberes específicos da docência são diferentes dos da pesquisa, razão pela qual não se defende a posição de conceder prioridade à competência científica em detrimento da competência pedagógica (MELO, 2004; CORDEIRO; MELO, 2008; PIMENTA; ANASTASIOU, 2002). 
Nesse trânsito de exigências e desafios quanto à construção da identidade profissional docente, aqui situada no âmbito da Educação Superior, outro aspecto que se deve levar em conta é as "cobranças" contidas nos Instrumentos de Avaliação dos processos regulatórios e avaliativos do Ministério de Educação, dispostas nos documentos do Sistema Nacional de Avaliação da Educação Superior (SINAES), nos quais as exigências em relação à titulação, produçóes e publicaçôes científicas se sobressaem às de formação pedagógica - o que, consequentemente, tem implicaçóes na (re)construção da identidade profissional do professor e ocasiona, talvez, crises de identidade entre o que é professor, o que é professor/pesquisador e o que é pesquisador. Dessa forma, é preciso que se façam indagaçōes do tipo: o que é ser professor? Que requisitos um professor precisa para exercer a docência na Educação Superior? O conhecimento específico disciplinar, a titulação e as publicaçóes científicas bastam para exercer a docência na Educação Superior? Que lugar ocupam os saberes pedagógicos nesse processo?

Não é propósito deste estudo responder a essas questóes, mas sim provocar reflexôes que instiguem o leitor a refletir sobre essa temática, uma vez que tais inquietações vão implicar no processo de (re)construção da identidade profissional docente.

Como pudemos observar, o processo de constituição da identidade profissional do professor é complexo, configura-se em diferentes tempos/ espaços/trajetórias, é individual e coletivo e não é um produto, mas uma construção de permanente reinvenção de relações pessoais, profissionais, experienciais e culturais compartilhadas. Ou, como diz Dubar (2005), é um processo de dupla transação biográfica e relacional.

Para finalizar, vale destacar uma questão a fim de instigar outros estudos a posteriori: sendo os profissionais docentes da Educação Superior detentores de conhecimentos específicos de outras profissóes que não a de docente, quais os possíveis caminhos para se construir uma identidade profissional docente enquanto identidade coletiva?

\section{Considerações (in)conclusivas}

No atual cenário educacional brasileiro, as mudanças, exigências e desafios que surgem ratificam a compreensão de que a identidade profissional docente não está dada de forma definitiva; ao contrário, vai se constituindo levando-se em conta sua permanente reconstruçấo. 
Vimos, neste estudo, que duas grandes correntes embasam conceitos de identidade: a Corrente Essencialista, que acredita nas essências e nas realidades essenciais; e a Corrente Existencialista, que postula que não há essências eternas, uma vez que tudo é submetido à mudança. Essa última visão reitera o nosso entendimento de que, num processo de construção identitária, as formas de identidade são inseparáveis das relações sociais, que são também formas de alteridade; ou seja, não existe identidade sem relação entre o si próprio e o outro. Para tanto, compartilhamos da visão de alguns estudiosos dessa temática (ERICKSON, 1972; LOPES, 2002; AGUIAR, 2004; MONTEIRO, 2004; DUBAR, 2005; dentre outros), ao corroborarem o conceito de identidade enquanto um processo que náo é estático, mas dinâmico, resultado de identificaçóes contingentes.

Nessa perspectiva, a identidade não é o alicerce da unidade de um grupo, ela é também resultante dos processos de identificação e de distinção pelos quais um grupo busca formar a sua coesão e marcar a sua posiçấo em relaçáo a outros grupos.

Como confirma Lopes (2001, p. 188), a identidade profissional é uma "identidade social particular que decorre do lugar das profissóes e do trabalho no conjunto social e, mais especificamente, do lugar de uma certa profissão e de um certo trabalho na estrutura da identidade pessoal e no estilo de vida do ator". Ao pensarmos na identidade profissional docente, reconhecemos que as identidades atribuídas a essa profissão têm se modificado mediante as circunstâncias e os interesses sociopolíticos de diferentes contextos, ora em prol da profissão, ora em detrimento de uma identidade que favoreça o status profissional docente.

No âmbito das reflexôes sobre a identidade profissional docente, particularmente daqueles que exercem a docência na educação superior, reconhecemos que esse processo está permeado por várias interaçóes, como, por exemplo, as histórias de vida dos professores, a formação e o conhecimento especializado do docente, as relaçóes com o grupo profissional, o conhecimento ou não das especificidades da profissão e de sua prática; e, ainda, pela singularidade dos sujeitos, dentre outros fatores relacionados à construção de uma identidade. Tal construção identitária está também vinculada às relaçōes com as instituiçóes empregadoras, às mudanças provenientes dos sistemas educacionais (AGUIAR, 2004), bem como ao contexto local em que o professor exerce a docência e à formação inicial (MONTEIRO, 2004) enquanto construção social. 
Como observamos, enfim, o processo de construção da identidade profissional docente é complexo e se constitui em diferentes espaços e tempos através de variadas trajetórias, sendo individual e coletivo, numa permanente reinvenção de relações pessoais e profissionais compartilhadas culturalmente.

\section{Notas}

${ }^{1}$ Neste texto, o termo "identidade" é utilizado no plural: "identidades".

${ }^{2}$ Refere-se aos professores formados em cursos de licenciatura para atuação docente na Educação Básica.

${ }^{3}$ Refere-se aos professores com curso superior de graduação que habilita para o exercício profissional.

${ }^{4}$ Cada professor participante da pesquisa foi identificado pela letra $\mathrm{P}$, seguido de um numeral, por exemplo: P1 primeiro professor a responder o questionário na instituição (pública ou privada).

\section{REFERÊNCIAS}

AGUIAR, Maria da Conceição Carrilho de. A formação contínua do docente como elemento na construção de sua identidade. 2004. Tese (Doutorado em Educação) - Universidade do Porto, Porto, 2004.

ARRUDA, Ana. Lúcia Borba de. Expansão da Educação Superior: uma análise do programa de apoio a planos de reestruturação e expansão das Universidades Federais (REUNI) na Universidade Federal de Pernambuco. 2011. 215 f. Tese (Doutorado em Educação) - Universidade Federal de Pernambuco, Recife, 2011.

BAUMAN, Zygmunt. Identidade. Rio de Janeiro: Zahar, 2005.

BAZZO, Vera Lúcia. Profissionalidade docente na educação superior: mestres ou cientistas? In: SEMINÁRIO DE PESQUISA EM EDUCAÇÃO DA REGIÃO SUL, 7., 2008, Itajaí. Anais... Itajaí, SC: UNIVALE, 2008.

CAMARGO, Marcela Pedroso de. Docência Universitária e Formação Pedagógica: um olhar para a Universidade Estadual de Londrina. 2012. 128 f. Dissertação (Mestrado em Educação) - Universidade Estadual de Londrina, Londrina, 2012. 
BRASIL. Lei n ${ }^{\circ}$ 9.394, de 20 de dezembro de 1996. Estabelece as diretrizes e bases da educação nacional. Diário Oficial da União, Brasília, DF, 23 dez. 1996.

CAPRA, Fritjof. A teia da vida: uma nova compreensão científica dos sistemas vivos. São Paulo: Cultrix, 1996.

CORDEIRO, Telma S. C.; MELO, Márcia Maria de O. (Org.). Formação pedagógica e docência do professor universitário. Recife: Editora da UFPE, 2008.

CUNHA, Maria Izabel da. Docência como ação complexa. In: CUNHA, Maria Izabel da. Trajetórias e lugares de formaçâo da docência universitária: da perspectiva individual ao espaço institucional. Araraquara, SP: Junqueira \& Marin, 2010.

DANTAS, Cecília Maria Macedo. O desenvolvimento da docência nas engenharias: um estudo na Universidade Federal de Campina Grande (UFCG). 2011. 106 f. Dissertação (Mestrado em Educação) - Universidade Federal do Rio Grande do Norte, Campo Grande, 2011.

D'ÁVILA, Cristina M. A construção da identidade profissional docente e o papel das disciplinas didático-pedagógicas na formação inicial de professores. In: DIAS, Ana Maria Iório et al. (Org.). Desenvolvimento Profissional Docente na Educação Superior: entre redes e sentidos. Fortaleza: Ediçôes UFC, 2009.

DOURADO, Luiz Fernandes. Reforma do Estado e as Políticas para a Educação Superior no Brasil nos anos 90. Educação \& Sociedade, Campinas, v. 23 , n. 80 , set. 2002.

DUBAR, Claude. A socialização: construção das identidades sociais e profissionais. São Paulo: Martins Fontes, 2005.

DUBAR, Claude. A Crise das Identidades: a interpretação de uma mutação. Porto, PT: Afrontamento, 2006.

ERIKSON, Erik. Genética: identidade e identificação. In: ERIKSON, Erik. Identidade, juventude e crise. Rio de Janeiro: Zahar, 1972 . p. 155-166

FRANCO, Maria Estela Dal Pai; GENTIL, Heloisa Salles. Identidade do professor de ensino superior: questóes no entrecruzar de caminhos. In: FRANCO, Maria Estela Dal Pai; KRAHE Elisabeth D. (Orgs). Pedagogia universitária e áreas de conhecimento. Porto Alegre: Série EdiPUCRS, 2007. p. 39-58. 
FREIRE, Paulo. Pedagogia da Autonomia: saberes necessários à prática educativa. Rio de Janeiro: Paz e Terra, 1997.

GENTILI, Pablo (Org.). Universidades em Penumbra: neoliberalismo e reestruturação universitária. São Paulo: Cortez, 2001.

LOPES, Amélia. Libertar o desejo, resgatar a inovação: a construção de identidades profissionais docentes. Lisboa: Instituto de Inovação Educacional, 2001.

LOPES, Amélia. Construção de Identidades Docentes e Selves Profissionais: um estudo sobre a mudança pessoal nos professores. Revista de Educação, Lisboa, v. 11, n. 2, 2002.

MELO, Márcia Maria de O. Política de formação dos profissionais da educação e a construçáo de uma nova cultura pedagógica na universidade. In: ENCONTRO NACIONAL DE DIDÁTICA E PRÁTICA DE ENSNO, 12., 2004, Curitiba. Anais... Curitiba:Champagnat, 2004. CDROM.

MONTEIRO, Ivanilde Alves. Formação inicial, identidade profissional e profissão docente: as representações sociais dos alunos do curso de Pedagogia da Universidade Federal de Pernambuco. Braga. 2004. Tese (Doutorado em Educação) - Universidade do Minho, Minho, PT, 2004.

MORIN, Edgar. Os desafios da complexidade. In: MORIN, Edgar (Org.). A religação dos saberes: o desafio do século XXI. Rio de Janeiro: Bertrand Brasil, 2001. p. 559-567

MORIN, Edgar. O Pensamento complexo, um pensamento que pensa. In: MORIN, Edgar; LE MOIGNE, Jean-Louis. A inteligência da complexidade. 3. ed. São Paulo: Peirópolis, 2000.

PIMENTA, Selma Garrido. Saberes pedagógicos e atividade docente. São Paulo: Cortez, 1999.

PIMENTA, Selma Garrido; ANASTASIOU, Lea das Graças C. Docência no Ensino Superior. São Paulo: Cortez, 2002.

ROMANELLI, Otaíza de Oliveira. História da educação no Brasil. Petrópolis: Vozes, 1997. 
SAINSAULIEU, Renaud. L'Identité au Travail. Paris: Presses de la Fondation Nationale des Sciences Politiques, 1985.

SCHEIBE, Leda Valorização e formaçáo dos professores para a educaçáo básica: questôes desafiadoras para um novo Plano Nacional de Educação. Educação \& Sociedade, Campinas, SP, v. 31, p. 981-1000, jul./set. 2010.

SERRALHEIRO, João Paulo. Introdução: o Processo de Bolonha e suas consequências. In: SERRALHEIRO, João Paulo (Org.). O Processo de Bolonha e a formação dos educadores e professores portugueses. Porto, PT: Profediçóes, 2005.

SOUZA, Jobeane Franca de. Identidade profissional do docente de licenciatura em Ciências Biológicas da UFS: desvelando os significados de ser professor. 2012. 164 f. Dissertação (Mestrado em Educação) - Universidade Federal da Paraíba, João Pessoa, 2012.

SUNDFELD, João Baptista. Formação de professores e o ensino superior: um estudo exploratório de uma instituição de formação de professores. 2005. 97 f. Dissertaçáo (Mestrado em Educação) - Pontifícia Universidade Católica de São Paulo, São Paulo, 2005.

TARDIF, Maurice. Saberes Docentes e Formação Profissional. Petrópolis, RJ: Vozes, 2002.

TARDIF, Maurice; LESSARD, Claude. O trabalho docente: elementos para uma teoria da docência como profissão de interaçóes humanas. Tradução de João batista Kreuch. 3. ed. Petrópolis, RJ: Vozes, 2007.

XIMENES, Aldeniza de Oliveira. A identidade profissional docente no ensino superior. 2006. 230 f. Dissertação (Mestrado em Educaçáo) - Universidade Federal de Pernambuco, Recife, 2006.

ZABALZA, Miguel A. O ensino universitário: seu cenário e seus protagonistas. Porto Alegre: Artmed, 2004. 


\section{L'identité professionnelle enseignante: les interfaces d'un processus en (re) construction}

\section{Résumé}

Le processus de (re)construction de l'identité professionnelle enseignante emmerge comme une thématique significative dont le centre d'étude implique la constitution de l'être professeur. Par ce biais, cette investigation a comme but réfléchir sur le processus de construction de l'identité professionnelle enseignante, pour favoriser une compréhension des aspects y compris. Pour faire ça, nous avons cherché des contributions d'études qui abordent cette thématique, notamment ceux rélatif à cette constitution dans le cadre de l'éducation supérieure. Ce travail, ancré dans l'approche qualitative de la recherche, a été partagé dans les thématiques suivantes: Les Concepts d'Identité et d'Identité Professionnelle, dans le sense de baser les réfléxions conçues tout au long de l'étude; et l'Identité Professionnelle Enseignante: les exigences et les défis circonstanciels, en soulignant ce processus dans l'Éducation Supérieure. Nous mettons en relief, dans les considérations (in) concluses, que l'identité n'est pas la fondation de l'unité d'un groupe, mas le résultat des processus d'identification et de distinction pour lesquels un groupe essaye de former sa cohésion et de marquer sa position en rapport
Docent's professional identity: interfaces of a process on (re)construction

\section{Abstract}

The process of (re)construction of the docent's professional identity emerges as an important theme which the studies' target involves the constitution of the being teacher. According with that, this investigation aims to think over the process of (re)construction of the docent's professional identity in order to support a comprehension of the aspects there involved. To do it, we searched some contributions from studies that approach this theme, in particular those focused on that constitution on the context of the college education. This work, grounded on the qualitative research approach, was categorized on the follows sections: Concepts of Identity and Professional Identity, which aims to support the thinking conceived during the study; and the Docent's Professional Identity: exigencies and circumstantial challenges, highlighting that process on the college education. We emphasize, on the (in) conclude considerations, that the identity is not the foundation of the homogeneity of a group, but the result of that same process of identity and distinction whereby a group searches to build its cohesion and to delimit its position in relation with other groups. The process of (re)construction of the docent's professional identity is complex and 
à d'autres groupes. Le processus de (re)construction de l'identité professionnelle enseignante est complexe et se constitue dans différents espaces et temps à travers des trajectoires variées, soient-elles individuelles ou collectives, dans une (re)invention permanente des rapports personnels et professionels partagés culturellement.

Mots-clés: Identité. Identité

Professionnelle Enseignante.

Éducation Supérieure. is constituted on different spaces and moments, through different trajectories, being individual and collective, on a permanent (re)invention of personal and professional relationships culturally shared.

Keywords: Professional identity. Teacher training. College Education.

\section{Maria da Conceiçáo Valença da Silva}

E-mail: conceicao.valenca@yahoo.com.br

\section{Maria da Conceiçáo Carrilho de Aguiar}

E-mail: carrilho1513@gmail.com

\section{Ivanilde Alves Monteiro}

E-mail: ivamonteiro@yahoo.com.br

Enviado em: 10/4/2013

Versão Final: 23/3/2014

Aprovado em: 25/3/2014 